\title{
Smoking versus infection as the aetiology of bronchial mucous gland hypertrophy in chronic bronchitis
}

\author{
GAMAL E. MEGAHED, GAMAL A. SENNA, \\ MOHAMMED H. EISSA, SAFEIA Z. SALEH, AND \\ HOUDA A. EISSA \\ From the Medical, Thoracic Surgery, Pathology, and Bacteriology Departments, Faculty of Medicine, \\ Cairo University, U.A.R.
}

\begin{abstract}
The smoking habits of 50 proved cases of chronic bronchitis were studied. Bronchoscopy was done and a bronchial biopsy was taken for histological examination. Bronchial lavage was obtained under sterile conditions for bacteriological studies. The degree of bronchial mucous gland hypertrophy was determined, and the presence or absence of infection, as shown by the presence of potential pathogens in the bronchial lavage, was noted. We think that tobacco smoking and its resulting irritation to the bronchi is the most important underlying cause of bronchial mucous gland hypertrophy because there is: (1) a significantly higher incidence of mucous gland hypertrophy in smokers than in non-smokers among the 50 chronic bronchitics studied; (2) a significantly higher accumulated lifetime tobacco consumption in patients exhibiting mucous gland hypertrophy than in those without hypertrophy of the bronchial mucous glands; (3) a significant association and correlation between the degree of mucous gland hypertrophy and the intensity of smoking; and (4) no difference in the comparative frequency of occurrence of bronchial mucous gland hypertrophy in subjects with and without demonstrable infection, as shown by the presence of potential pathogens in the bronchial lavage. We could not deny that infection might be having an initiating or potentiating effect.
\end{abstract}

The characteristic feature of chronic bronchitis is an excessive secretion of mucus, which provokes cough and expectoration. This mucus secretion is mainly a function of the bronchial mucous glands. Glynn and Michaels (1960), Reid (1960), and Restrepo and Heard (1963a, b) demonstrated enlargement of the mucous glands in chronic bronchitis. Glynn and Michaels (1960) showed that the pathological features consisted of an increase both in the number of mucous relative to serous glands and in the size of the mucous acini due to swelling of their component cells and their lumina. They suggested that this mucous change is probably the result of transformation of serous into mucous acini, followed by an increase in size of the latter. They considered that this mucous change of the deep glands is the most important pathological feature of chronic bronchitis. Reid (1960) found that the amount of sputum produced by the chronic bronchitic was well correlated with the degree of mucous gland hypertrophy. To investigate the role of smoking in inducing this mucous gland hypertrophy, Thurlbeck, Angus, and Paré (1963) examined bronchi from necropsies and grouped cases according to smoking habits. They found that the Reid gland: wall ratio was significantly higher in heavy smokers than in non-smokers.

The aim of the present work was to study the correlation between the degree of hypertrophy of the bronchial mucous glands, as shown by bronchial biopsies obtained from chronic bronchitics, and the smoking habits of these patients or the presence of infecting pathogens in the bronchial tree, in an attempt to evaluate the roles of tobacco irritation and infection in the production of this mucous change in the bronchial glands.

\section{METHODS AND MATERIALS}

Fifty men with chronic bronchitis admitted to the Medical Department, Cairo University Hospitals, constitute the subject of the present study. This confinement to the male sex was not due to selection on our part, for in the period from October 1962 to May 1964, during which these cases were studied, not a single female chronic bronchitic presented to us. The ages of the patients ranged from 25 to 70 years, with an average of 47.2 years. The diagnosis of chronic bronchitis was based on the Ciba Guest 
Symposium (1959) definition--'the production of phlegm on at least four days a week for three months of a year for at least three years'. Plain radiography of the chest and bronchography was done in each case. Cardiac patients presenting with chronic cough, patients with bronchiectasis, genuine asthmatics, and patients in whom investigations disclosed a specific cause for the chronic cough were excluded. A careful history of the smoking habits was obtained by two of us to cross-check the data. Patients were asked whether they smoked. Smokers were asked about the duration of their smoking habit and the type of smoking practised. Some smoked cigarettes, others 'gouza', a peculiar smoking habit prevalent among our patients, and a third group smoked both cigarettes and gouza. None smoked pipes or cigars. Each time a patient smoked gouza this was considered to be equivalent to the smoking of two cigarettes. Any error produced by such an assumption would not affect the results materially. Patients whose answers were variable were not included in this study. The accumulated lifetime tobacco consumption was calculated for each patient by multiplying his average daily consumption of cigarettes, or cigarette equivalent of 'gouza', or both, by the duration of the period he smoked. Patients were graded according to the intensity of their smoking habit as follows:

DAILY TOBACCO CONSUMPTION

\begin{tabular}{c|c}
\hline Grade & Cigarettes/day \\
\hline 0 & Non-smokers \\
1 & $1-$ \\
2 & $10-$ \\
3 & $30-$ \\
4 & $50+$
\end{tabular}

ACCUMULATED LIFETIME TOBACCO CONSUMPTION

\begin{tabular}{c|c}
\hline Grade & Cigarettes (thousands) \\
\hline 0 & Non-smokers \\
1 & $1-$ \\
2 & $200-$ \\
3 & $400-$ \\
4 & $600+$ \\
\hline
\end{tabular}

BRONCHOSCOPIC TECHNIQUE All instruments used in bronchoscopy were sterilized by autoclaving before use. Patients were seen in the morning after a 12 hours' fast. They were given a premedication of intramuscular phenobarbitone and atropine sulphate one hour before the procedure. The bronchoscope was introduced under tetracaine hydrochloride surface anaesthesia. After general visual endoscopy, bronchial lavage with sterile saline, using a sterile syringe and injecting it through the bronchoscopic aspirating tube in the main bronchi, was performed. A few seconds later aspiration was done after asking the patient $t \overrightarrow{\overline{\vec{m}}}$ cough, and the lavage was collected in a Luken'e specimen collector, which was then sent to the bacteris ologist. This laborious aseptic sterile technique was adopted and bronchial lavage preferred for bacterio logical studies in our patients, since we were aware that bacteriological examination of the sputum of throat swab is misleading due to contamination by potential pathogens of the nasopharynx, which mas occur in patients with no bronchial infection, and thus. be a source of error as demonstrated by Master Brumfitt, Mendez, and Likar (1958) and Laurenzit Potter, and Kass (1961). Brumfitt, Willoughby, an Bromley (1957) had found that normal bronchfo swabbed directly through a bronchoscope wereu sterile, whereas Haemophilus influenzae was isolated from 18 of 19 chronic bronchitics.

A loopful of the bronchial lavage obtained was inoculated on to duplicate plates of blood agar, one. of which was inoculated aerobically and the other anaerobically at $37^{\circ} \mathrm{C}$. After 24 hours' incubatio plates were examined for growth. All organisms were. identified by visual examination and smear. Staphylo cocci were tested for ability to produce coagulase by the tube method using rabbit antiserum. Att coagulase-positive strains were recognized by the production of haemolysin on blood agar plates Pneumococci were injected into mice and the pos mortem picture was studied. Strains of $\boldsymbol{H}$. influenzag were identified by their morphology and indole prø duction. Gram-negative rods were identified by sub culture on differential media and biochemical reaction.

$H$. influenzae, Staphylococcus aureus, and pneume् cocci were considered to be the most important potential pathogenic organisms for the bronchi, as reported by Dowling, Mellody, Lepper, and Jacksog (1960) and Cherniack, Vosti, Dowling, Lepper, and Jackson (1959). Neisseria catarrhalis, diphtheroids and streptococci of the viridans and indifferent varieties were ignored. Streptococci of the $\beta$-haem lytic variety and Klebsiella pneumoniae, althougi of lesser importance and occurring less frequently were also considered as potential pathogens. Our 50 chronic bronchitics were then classified into two groups:

Group $A$ This group comprised 28 patients. An one or more of the potentially pathogenic organisnto was isolated from the bronchial lavage.

Group $B$ This group consisted of 22 patients Infection of the bronchial tree could be excluder because none of these pathogens was present in the bronchial lavage.

Bronchoscopic biopsy was taken with a Brock's biopsy forceps under vision from the main carine The specimens obtained were fixed in $10 \%$ formalim solution, embedded in paraffin, and cut at $5 \%$ intervals.

A record of the main histological features in each case was made without knowledge of the clinica history or smoking habit of the patient. Broncho 
scopic biopsies were also taken in the same way from five normal adult males, and were stained and used as controls in assessing variations seen in the biopsy materials. The ages of these control subjects were 30 , $39,47,54$, and 60 years respectively.

The 50 cases studied were graded according to the state of the bronchial mucous glands as follows:

Grade 0 No mucous glands or only a small number of normal mucous glands were seen in the sections examined. This group comprised 15 patients. In two of these, serous glands predominated, with a small number of normal mucous glands. In three patients a small number of serous glands only were seen in the sections. In the remaining 10 patients no serous or mucous glands were present in the sections examined.

Grade 1 Only a slight increase in the number of mucous glands was seen. This group comprised four patients.

Grade 2 An increase in the number of mucous glands was obvious, with numerous serous acini and demilunes. This group comprised nine patients.

Grade 3 The mucous glands were found to be hypertrophied and of greater diameter than normal.

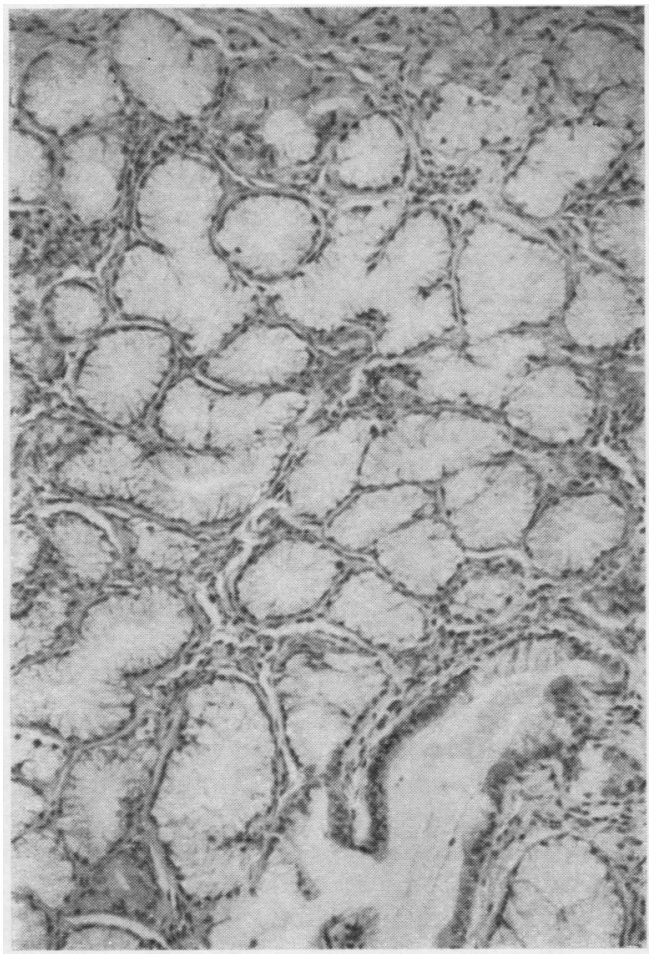

FIG. 1. All deep glands are hypertrophied mucous glands with no serous glands or demilunes, i.e., there is an increase in the number and size of the mucous acini and a disappearance of serous cells.
The cells of the acini were taller and wider and their cytoplasm less basophilic. The cells were also overdistended with mucus rather than showing an excessive discharge into the lumen, but occasionally a mucous discharge in the lumen was present and the gland therefore appeared as small flat cells enclosing a lumen filled with mucus. In addition, a few serous acini and demilunes were found. This group comprised 15 patients.

Grade 4 Hypertrophied mucous glands, as described in grade 3, were seen, but with complete replacement of the normally predominant serous glands, so that there were no serous glands or demilunes as in grade 3 . This group comprised seven patients (Figs 1 and 2).

It is worth noting that the five normal control subjects showed no evidence of developing either hypertrophy or atrophy of the bronchial mucous glands with age.

\section{RESULTS}

Statistical comparison of the relative frequency of occurrence of mucous gland hypertrophy among

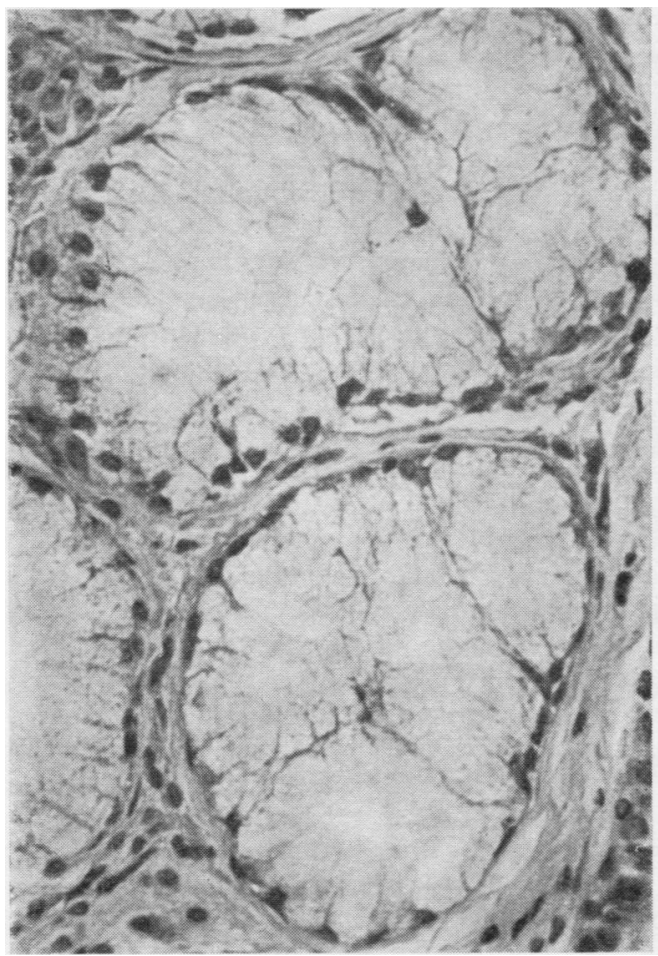

FIG. 2. High-power view of Fig. 1 to show the hypertrophied mucous glands. The mucous glands are greater in diameter than normal. The cells are taller and wider than normal and are overdistended with mucus. 
T A B LE I

MUCOUS GLAND HYPERTROPHY IN SMOKERS AND NON-SMOKERS AMONG CHRONIC BRONCHITICS

\begin{tabular}{|c|c|c|c|c|c|c|c|}
\hline & \multirow[t]{2}{*}{. } & \multicolumn{2}{|c|}{$\begin{array}{c}\text { Mucous } \\
\text { Gland } \\
\text { Hypertrophy }\end{array}$} & \multicolumn{2}{|c|}{$\begin{array}{c}\text { No Mucous } \\
\text { Gland } \\
\text { Hypertrophy }\end{array}$} & \multirow{2}{*}{ Total } & \multirow{2}{*}{$\mathbf{P}$} \\
\hline & & No. & $\begin{array}{l}\text { Per } \\
\text { cent. }\end{array}$ & No. & $\begin{array}{l}\text { Per } \\
\text { cent. }\end{array}$ & & \\
\hline $\begin{array}{l}\text { Smokers . } \\
\text { Non-smokers }\end{array}$ & $\cdots$ & $\begin{array}{r}33 \\
2\end{array}$ & $\begin{array}{l}77 \\
29\end{array}$ & $\begin{array}{r}10 \\
5\end{array}$ & $\begin{array}{l}23 \\
71\end{array}$ & $\begin{array}{r}43 \\
7\end{array}$ & 0.02 \\
\hline
\end{tabular}

smokers (43) and non-smokers (7) in the 50 cases of chronic bronchitis studied, using Fisher's exact test for $2 \times 2$ tables, has shown a significantly higher incidence of mucous gland hypertrophy in smokers $(77 \%)$ than in non-smokers $(29 \%)$, $\mathbf{P}=\mathbf{0 . 0 2}$, as shown in Table I. In fact out of the 35 cases showing mucous gland change, only two patients were non-smokers, and it is of interest to note that both were workers in dusty occupations, the first an agricultural labourer and the second a labourer on unpaved dusty high roads in the countryside.

To study the relation between the degree of mucous change of the bronchial glands and the degree of intensity of the smoking habit, we compared statistically the average accumulated lifetime tobacco consumption of patients showing mucous gland hypertrophy with that of patients in whom no change was detected in the bronchial glands, using Student's ' $t$ ' test. It was found that the average accumulated lifetime tobacco consumption among patients with mucous gland hypertrophy (33 cases) $-275,000$ cigarettes, S.D. 194,000 -was significantly higher than among patients in whom no such hypertrophy was observed (10 cases)-133,000 cigarettes, S.D. $106,000-\mathrm{P}<0.05$.

As a further study of the association between the degree of mucous change of the bronchial glands and the degree of intensity of the smoking habit, we used the chi-square test. We compared the relative frequency of incidence of marked mucous change in the bronchial glands (grades 3 and 4 of our classification) in non- or light smokers (grades 0 and 1 of our classification-those whose accumulated lifetime tobacco consumption was found to be less than 200,000 cigarettes) and in heavier smokers-those who smoked more than 200,000 cigarettes (grades 2,3 , and 4 of our classification). It was found that among those who smoked less than 200,000 cigarettes ( 29 cases) only nine $(31 \%)$ showed marked mucous change of the bronchial glands, whereas of the 21 patients who smoked more than 200,000 cigarettes, 13
$(62 \%)$ showed marked mucous change of the bronchial glands. This difference was found by the chi-square test to be statistically significant $(\mathrm{P}=0.03)$.

Since we classified our patients according to the state of the bronchial mucous glands into five grades, $0,1,2,3$, and 4 , and similarly classifiee them according to their daily and accumulate $\bar{b}$ lifetime tobacco consumption, as previously mentioned, we tried to find out if there was a signi ficant correlation. In other words, we wanted to see if the state of the bronchial mucous glands could be correlated with the intensity of the smoking habit as measured by the degree of dailye or accumulated lifetime tobacco consumption This was done by calculating the correlation $\mathrm{cos}_{\mathrm{B}}$ efficient, $r$, assuming that all readings fall at the centre of the groups. To make sure that the obtained measure of agreement could not arise by chance, we tested the significance of the obtained correlation coefficient by using Student's ' $t$ ' tes The $t$ was computed by the formula:

$$
\text { Student's } t=\frac{r \sqrt{n-2}}{\sqrt{1-r^{2}}}
$$

with $n-2$ degrees of freedom, and thus the level significance (P) of the correlation coefficient conts puted could be ascertained.

The result has shown a significant, moderate positive correlation coefficient $(r+0.335$ and $P<0.02$ ) between the degree of change of the bronchial glands as detected in the biopsy spec? mens and the degree of intensity of the smoking habit as measured by the accumulated lifetime tobacco consumption. A similar, significan moderate positive correlation coefficient $(r+0.328$ and $P<0.02$ ) was found between the degree of mucous change of the bronchial glands and the degree of intensity of the smoking habit as measured by the daily tobacco consumption. This. further clarified the role of smoking in producings hypertrophy of the mucous glands in chronic bronchitis.

In order to test the role of infection as a aetiological factor in bronchial mucous glang hypertrophy, we statistically compared the frequency of occurrence of mucous gland hyperg trophy in our chronic bronchitic patients with and without demonstrable infection, as evidenced b? the isolation of pathogens on culture of bronchiag lavage, using a contingency chi-square test, क $\$$ shown in Table II. It was found that the incidence of mucous gland hypertrophy in the 28 patiens with demonstrable infection $(71.5 \%)$ was similam 
T A B L E II

MUCOUS GLAND HYPERTROPHY IN CHRONIC BRONCHITICS WITH AND WITHOUT DEMONSTRABLE INFECTION

\begin{tabular}{|c|c|c|c|c|c|c|c|}
\hline & \multicolumn{2}{|c|}{$\begin{array}{c}\text { Mucous } \\
\text { Gland } \\
\text { Hyper- } \\
\text { trophy }\end{array}$} & \multicolumn{2}{|c|}{$\begin{array}{c}\text { No } \\
\text { Mucous } \\
\text { Gland } \\
\text { Hyper- } \\
\text { trophy }\end{array}$} & \multirow[t]{2}{*}{ Total } & \multirow[t]{2}{*}{$x^{2}$} & \multirow[t]{2}{*}{$\mathbf{P}$} \\
\hline & No. & $\%$ & No. & $\%$ & & & \\
\hline $\begin{array}{c}\text { With demonstrable in- } \\
\text { fection }\end{array}$ & 20 & $71 \cdot 5$ & 8 & $28 \cdot 5$ & 28 & \multirow{2}{*}{0.005} & \multirow{2}{*}{0.95} \\
\hline $\begin{array}{c}\text { With no demonstrable } \\
\text { infection }\end{array}$ & 15 & $68 \cdot 5$ & 7 & $31 \cdot 5$ & 22 & & \\
\hline
\end{tabular}

to its incidence $(68.5 \%)$ in the 22 patients with no pathogens cultured from the bronchial lavage. This difference in incidence is insignificant, and the two groups are almost identical.

To study the role of infection further, and whether it potentiates the effect of smoking, Table III was constructed. We compared the incidence of bronchial mucous gland hypertrophy in patients who smoked more and less than 40,000 cigarettes, among patients in whom infection of the bronchial tree was or was not found. The level of significance of the comparative frequency of incidence of bronchial mucous gland hypertrophy in the compared groups was calculated using Fisher's exact test for $2 \times 2$ tables. This pair of tables shows that whether infection was or was not found, the incidence of mucous gland hypertrophy was significantly higher in those who smoked more than 40,000 cigarettes than in those who smoked less than this amount.

T A B L E I I I

MUCOUS GLAND HYPERTROPHY IN CHRONIC BRONCHITIS WITH AND WITHOUT DEMONSTRABLE BRONCHIAL INFECTION, IN THOSE WHO SMOKED MORE AND LESS THAN 40,000 CIGARETTES

\begin{tabular}{|c|c|c|c|c|}
\hline \multirow{2}{*}{$\begin{array}{c}\text { Total } \\
\text { Cigarette } \\
\text { Consumption }\end{array}$} & \multicolumn{2}{|c|}{ Grade of Mucous Glands } & \multirow{2}{*}{ Total } & \multirow{2}{*}{$\mathbf{P}$} \\
\hline & 0 & $1,2,3,4$ & & \\
\hline \multirow[t]{2}{*}{$\begin{array}{c}\text { Infection found } \\
>40,000 \\
<40,000\end{array}$} & $\begin{array}{l}3 \\
5\end{array}$ & $\begin{array}{r}18(85.7 \%) \\
2(28.5 \%)\end{array}$ & $\begin{array}{r}21 \\
7\end{array}$ & \multirow[t]{2}{*}{0.017} \\
\hline & 8 & $20(71 \cdot 7 \%)$ & 28 & \\
\hline \multirow[t]{2}{*}{$\begin{array}{c}\text { No infection found } \\
>40,000 \\
<40,000\end{array}$} & $\begin{array}{l}3 \\
4 \\
\end{array}$ & $\begin{aligned} & 15(83 \cdot 3 \%) \\
& 0(0 \%)\end{aligned}$ & $\begin{array}{r}18 \\
4\end{array}$ & \multirow[t]{2}{*}{0.008} \\
\hline & 7 & $15(68 \cdot 2 \%)$ & 22 & \\
\hline
\end{tabular}

This also shows that those who smoked more than 40,000 cigarettes had a similar incidence of hypertrophy of the mucous glands, whether infection was or was not present, i.e., the incidence of mucous gland hypertrophy was not affected by the presence or absence of infection
TA B LE I V

MUCOUS GLAND HYPERTROPHY IN THOSE WHO SMOKED MORE AND LESS THAN 40,000 CIGARETTES WHETHER BRONCHIAL INFECTION WAS OR WAS NOT FOUND

\begin{tabular}{|c|c|c|c|c|}
\hline \multirow{2}{*}{$\begin{array}{c}\text { Cigarette } \\
\text { Consumption }\end{array}$} & \multicolumn{2}{|c|}{ Grade of Mucous Glands } & \multirow{2}{*}{ Total } & \multirow{2}{*}{$\mathbf{P}$} \\
\hline & $\mathbf{0}$ & $1,2,3,4$ & & \\
\hline \multirow[t]{2}{*}{$\begin{array}{l}>40,000 \\
\quad \text { Infection } \\
\text { No infection ... }\end{array}$} & $\begin{array}{l}3 \\
3\end{array}$ & $\begin{array}{l}18(85.7 \%) \\
15(83.3 \%)\end{array}$ & $\begin{array}{l}21 \\
18\end{array}$ & \multirow[t]{2}{*}{0.67} \\
\hline & 6 & $33(84 \cdot 6 \%)$ & 39 & \\
\hline \multirow[t]{2}{*}{$\begin{array}{l}<40,000 \\
\quad \text { Infection } \\
\quad \text { No infection .. }\end{array}$} & $\begin{array}{l}5 \\
4\end{array}$ & $\begin{array}{l}2(28.5 \%) \\
0(0 \%)\end{array}$ & $\begin{array}{l}7 \\
4\end{array}$ & \multirow[t]{2}{*}{0.76} \\
\hline & 9 & $2(18 \cdot 1 \%)$ & 11 & \\
\hline
\end{tabular}

as shown by the next pair of tables (Table IV). Although this table does not show statistically significant evidence that in patients who smoked less than 40,000 cigarettes infection has a potentiating effect, yet the apparent effect is potentiation. Mucous gland hypertrophy was observed in $28.5 \%$ of patients (two out of seven) when infection was found. When no infection was found (four patients) no case showed mucous gland hypertrophy. This apparent potentiating effect of infection cannot be dismissed simply because the number of patients in this group is small.

The fact that the effect of infection is nonsignificant does not permit infection to be dismissed, for non-significance does not mean nonexistence. In order to dismiss infection as a factor one would need a confidence integral for a parameter which describes the effect of infection, and would need to show that only a negligible effect is compatible with the observations.

However, suppose that one writes:

$\mathrm{p}_{1}=$ probability that the mucous glands are normal in an infected light or non-smoker

$\mathrm{p}_{2}=$ probability that the mucous glands are normal in an uninfected smoker

$\mathrm{p}_{3}=$ probability that the mucous glands are normal in an infected smoker

Then consider the evidence for or against the following hypothesis:

$\mathrm{p}_{3}=\mathrm{p}_{1} \mathrm{p}_{2}$ (i.e., smoking and infection act independently)

Tables III and IV can be rearranged as a table of the incidence of normal mucous glands, as follows :

\begin{tabular}{l|c|c}
\hline & \multicolumn{2}{|c}{ CIGARETTE CONSUMPTION } \\
\cline { 2 - 3 } & $<40,000$ & $>40,000$ \\
\cline { 2 - 3 } Infection & $5 / 7=0.71$ & $3 / 21=0.14$ \\
No infection & $4 / 4=1.00$ & $3 / 18=0.17$ \\
\hline
\end{tabular}


The data suggest that hypertrophy is rare when both infection and heavy smoking are absent, and that $p_{1} \simeq 0.71, p_{2} \simeq 0.17$. These two values give $\mathrm{p}_{1} \mathrm{p}_{2}=0 \cdot 12$, giving an expectation of 2.52 normal cases in the 21 infected heavy smokers according to the hypothesis $p_{3}=p_{1} p_{2}$. The observed number is three (i.e., $14 \%$ against the theoretical $12 \%$ ), which agrees well with the hypothesis. Therefore one should not dismiss infection as an associated aetiological agent.

\section{DISCUSSION}

The present study clearly shows that smoking is an important underlying aetiological basis for the mucous gland hypertrophy seen in chronic bronchitics as evidenced by:

(1) the significantly higher incidence of mucous gland hypertrophy in smokers than in nonsmokers among the 50 chronic bronchitics studied. In fact, out of the 35 cases with mucous gland hypertrophy only two, i.e., $5 \cdot 7 \%$, were nonsmokers. These two patients were found to be labourers in dusty occupations, where the irritation of inhaled dust replaced the irritation of inhaled tobacco smoke in producing mucous gland hypertrophy ;

(2) the significantly higher average accumulated lifetime tobacco consumption in patients with mucous gland hypertrophy than in those without such a change ;

(3) the significant association between the degree of mucous change of the bronchial glands and the intensity of the smoking habit as shown by the chi-square test ;

(4) the significant correlation between the degree of mucous gland hypertrophy and the degree of intensity of the smoking habit, as measured by the daily or accumulated lifetime tobacco consumption.

Since we obtained histological material from each patient on a single occasion only, we cannot state whether the glandular hypertrophy that we studied is permanent or reversible. If the hypertrophy is irreversible, it may be argued that there will tend to be more hypertrophy in persons with a large total of cigarettes smoked, simply because this total is also irreversible, that is, hypertrophy and the total smoking will tend to have a positive correlation because both tend to be higher in older than in younger people. To answer this argument, the average age of smokers with bronchial mucous gland hypertrophy (33 cases) was found to be 49.3 years (S.D. 10.9), and the average age of smokers with no mucous gland hypertrophy (10 cases) $42 \cdot 7$ years (S.D. 12). The difference of 6.6 years between the two means however, tested by the ' $\mathrm{t}$ ' test proved to be insig nificant (P 0.1). Similarly, a calculation of $95 \%$ confidence limits for the true mean age of botto groups of smokers with or without bronchiaf mucous gland hypertrophy was carried out. The $95 \%$ confidence interval of the true mean age fop smokers with mucous gland hypertrophy was. found to be from 45.43 years to 53.17 years, and for smokers with no mucous gland hypertroph from 34.12 to 51.28 years. The difference in true mean ages may be as large as 19 years in on direction or, alternatively, as much as 5.85 year in the opposite direction. The usual theory of con $\exists$ fidence limits is a little shaky on data such as these, but the essential point is that although the observed difference (6.6 years) is not significant one cannot discount the existence of a real differ ence in the same direction. The question, how $=$ ever, is whether hypertrophy tends to increase with age so fast that the difference of 6.6 years can account for the observed differences in the incidence of bronchial mucous gland hypertrophys Our five normal control subjects showed no evio dence of either hypertrophy or atrophy of the bronchial mucous glands developing with age.

We similarly compared the incidence of bron chial mucous gland hypertrophy, using contin 3 gency tables based on two dividing lines for the ages of the patients, namely, 45 and 55 years, an $\bar{\phi}$ applied Fisher's exact test for $2 \times 2$ tables, to find if there was any significant difference in the incidence of mucous gland hypertrophy above an below these dividing lines (Table V). The differe ences again were found to be not significant.

T A B L E V

MUCOUS GLAND HYPERTROPHY IN SMOKERS UNDER

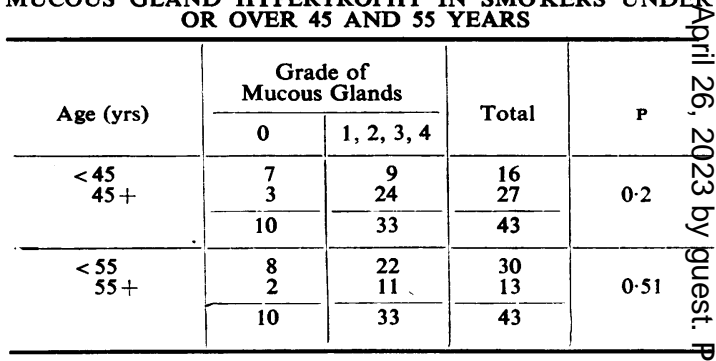

This lack of correlation between age and mucous gland hypertrophy may be explaines by the variability of age when smoking was begun and of the average daily cigarette consumption in the different patients. The 
average age at starting to smoke was 22 years, but the range extended from 8 years (case 32) to 50 years (case 2). Thus it is clear that the total cigarette consumption is not a combined index of smoking and age but of the daily cigarette consumption and the duration of the smoking habit. In other words, the correlation between smoking and bronchial mucous gland hypertrophy is a true one and is not simply a function of the age of the patient.

Since some occupations may predispose to chronic irritation of the tracheobronchial tree and might be the underlying cause of hypertrophy of the bronchial mucous glands rather than smoking, we compared the occupations of the patients with and without mucous gland hypertrophy, as shown in Table VI, and no difference was observed between the two groups.

\section{T A B L E V I}

OCCUPATION OF CHRONIC BRONCHITIC PATIENTS STUDIED, WITH AND WITHOUT BRONCHIAL MUCOUS GLAND HYPERTROPHY

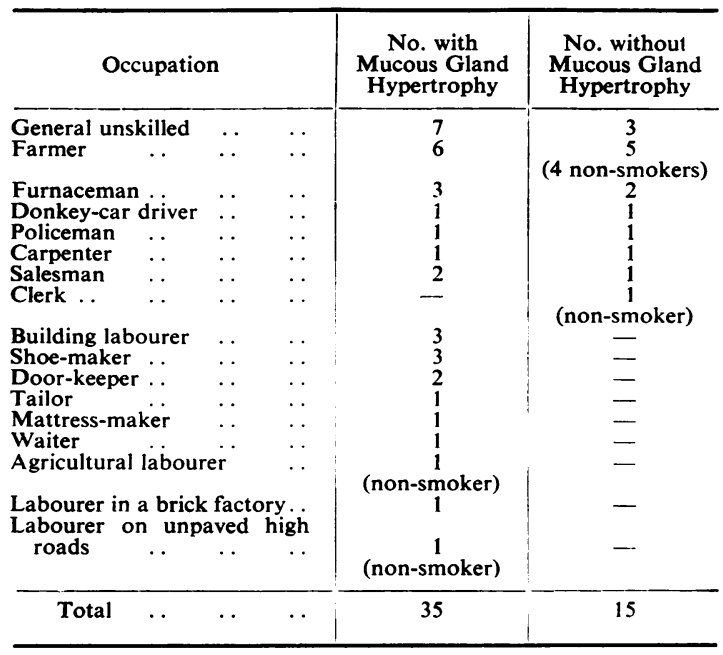

That chronic bronchitis observed during the period of this study was confined (without selection on our part) to the male sex is also further evidence in favour of the role of smoking. In our country, smoking is very rare in women and is almost unknown in our hospital class of female patients.

Our findings are in agreement with the necropsy study of the bronchi carried out by Thurlbeck et al. (1963), who grouped cases according to their smoking habits and found that the Reid (1960) gland: wall ratio was significantly higher in heavy smokers than in non-smokers. Glynn and Michaels (1960) found smoking to be more common (7 out of 16) among patients having mucous gland excess than in those with serous gland excess ( 2 out of 14). They commented, however, that information about smoking habits in their patients was incomplete and that it would be unwise to stress the difference between the two groups. They also could find no relation between smoking and the degree of mucous conversion, and suggested that tobacco is not the immediate cause of mucous change of the bronchial glands.

Since mucous gland hypertrophy, as suggested by Glynn and Michaels (1960), is the cardinal pathological feature in chronic bronchitis, the present study points to the importance of smoking as an aetiological factor in this disease. This agrees with the observations of Oswald and Medvei (1955) and Palmer (1954) that bronchitis is more common among smokers than nonsmokers.

The present study could not show that infection has a role in the causation of mucous change of the bronchial glands in chronic bronchitis. This may point to the greater importance of smoking as an aetiological factor in this disease and is in agreement with the views of Greene and Berkowitz (1954), who reported smoking to be four to seven times more common a cause of chronic bronchitis than all other causes combined. In fact, in a study of the role of smoking in chronic bronchitis in Egyptians, one of us (G. E. M.) found by comparing the smoking habits of chronic bronchitics and control nonbronchitic subjects that a critical upper limit value of accumulated lifetime tobacco consumption equivalent to 300,000 cigarettes existed, above which all smokers were chronic bronchitics. This is equivalent to the smoking of two packets of cigarettes daily for 20 years. Yet one cannot completely rule out the role of infection, which might be having an initiating or potentiating effect that is difficult to ascertain on the basis of the present data.

\section{REFERENCES}

Brumfitt. W., Willoughby, M. L. N., and Bromley, L. L. (1957). An evaluation of sputum examination in chronic bronchitis. Lancet,
2,1306 .

Cherniack, N. S., Vosti, K. L., Dowling, H. F., Lepper, M. H., and Jackson, G. G. (1959). Long-term treatment of bronchiectasis and chronic bronchitis. Arch. intern. Med., 103, 345.

Ciba Guest Symposium (1959). Terminology, definitions, and classification of chronic pulmonary emphysema and related condi-
tions. Thorax 14,286 .

Dowling, H. F., Mellody, Margaret, Lepper, M. H., and Jackson, G. G. (1960). Bacteriologic studies of the sputum in patients with chronic bronchitis and bronchiectasis. Amer. Rev. resp. Dis., 81, 329. Glynn, A. A., and Michaels, L. (1960). Bronchial biopsy in chronic
bronchitis and asthma. Thorax, 15, 142. 
Greene, B. A., and Berkowitz, S. (1954). Tobacco bronchitis: an anesthesiologic study. Ann. intern. Med., 40, 729.

Laurenzi, G. A., Potter, R. T., and Kass, E. H. (1961). Bacteriologic flora

Masters, P. L., Brumfitt, W., Mendez, R. L., and Likar, M. (1958) Bacterial filora of the upper respiratory tract in Paddington families, 1952-54. Brit. med. J., 1, 1200.

Megahed, Gamal E. (1967). The role of smoking in chronic bronchitis in Egyptians - to be published.

Oswald, N. C., and Medvei, V. C. (1955). Chronic bronchitis, the effect of cigarette-smoking. Lancet, 2, 843 .
Palmer, K. N. V. (1954). The role of smoking in bronchitis. Brit. med J., 1, 1473.

Reid, L. (1960). Measurement of the bronchial mucous gland lay a diagnostic yardstick in chronic bronchitis. Thorax 15, 132.

Restrepo, G. L., and Heard, B. E. (1963a). Mucous gland enlargement in chronic bronchitis: extent of enlargement in the tracheo bronchial tree. Ibid., 18, 334 . bronchitis. J. Path. Bact., 85, 305 .

Thurlbeck, W. M., Angus, G. E., and Paré, J. A. P. (1963). Mucoư gland hypertrophy in chronic bronchitis, and its occurrence in smokers. Brit. J. Dis. Chest, 57, 73. 